\title{
Construction of a New Sensor with Ruthenium Complex Anchored in Functionalized Silica and Their Application in Determination of Ascorbic Acid in Industrial Fruit Juice
}

\author{
Mauricio Guilherme Vieira, Gabriel de Souza, Gilberto Henrique Bardini Aristides, \\ Larissa Voleck Lopes, Angélica Machi Lazarin
}

Department of Chemistry, State University of Maringá, Avenue Colombo, Maringá, PR, Brazil

\section{Email address:}

amlazarin2@uem.br(A. M. Lazarin)

\section{To cite this article:}

Mauricio Guilherme Vieira, Gabriel de Souza, Gilberto Henrique Bardini Aristides, Larissa Voleck Lopes, Angélica Machi Lazarin. Construction of a New Sensor with Ruthenium Complex Anchored in Functionalized Silica and Their Application in Determination of Ascorbic Acid in Industrial Fruit Juice. International Journal of Sensors and Sensor Networks. Vol. 5, No. 2, 2017, pp. $27-33$. doi: $10.11648 /$ j.ijssn.20170502.12

Received: June 9, 2017; Accepted: June 27, 2017; Published: July 20, 2017

\begin{abstract}
The chemically modified silica gel with 3-aminopropyltrimethoxysilane groups and EDTA was used to immobilize ruthenium complex initially. These materials were incorporated into a carbon paste electrode and its electrochemical properties were investigated. However, for ascorbic acid solution, an enhancement of the anodic peak current was detected due to electrocatalytic oxidation. The electrodes presented good repeatability, stability and reproducible. The sensors were applied in ascorbic acid determination in industrial fruit juice with success.
\end{abstract}

Keywords: Silica Gel, 3-Aminopropyltrimethoxysilane, Carbon Paste Electrode, Ruthenium Complex, Ascorbic Acid

\section{Introduction}

The development of chemically modified electrodes (CME) and their application in electroanalytical techniques have been extensively revised [1, 2]. The chemically modified electrodes have characteristics such as: selectivity, high sensitivity and simplicity of monitoring the analyte of interest, without previous treatment of the sample [3].

There is also a great interest in the modification of silicas by organic compounds that can act as ligands for the coordination of metallic ions in theirsurface and used in the construction of chemically modified electrodes of carbon paste electrodes (CPE), in the study of the electrochemical behavior of these anchored complexes, in electroanalysis and electrocatalysis [1-7].

The advantages of the use of organofunctionalized silica, containing on its surface the sequestering agent for transition metals are related to their high thermal stability, the accessibility of reactive centers and its insolubility in organic means $[8,9]$.

The present investigation, new ruthenium complexes were supported on the surface of chemically modified silicas and the carbon paste electrode (EPC) was constructed by incorporating one of these silicas into the graphite.

The anchorage of the ruthenium complex was through the reaction of $\mathrm{RuCl}_{3} \times \mathrm{H}_{2} \mathrm{O}$, in ethanolic means with the SF3APTS/EDTA silica and also by the reaction of this silica with the $\mathrm{H}\left[\mathrm{Ru}(\mathrm{III}) \mathrm{Cl}_{2}\left(\mathrm{H}_{2}\right.\right.$ EDTA $\left.)\right]$ complex, previously synthesized [10].

The use of cyclic voltammetry and / or differential pulse voltammetry with chemically modified electrodes as a working electrode may be an efficient and very sensitive analytical method (addition of standard and / or analytical curve) for the study of electrocatalytic oxidation of reagents of biological interest. Such as ascorbic acid (AA), dopamine (3,4-dihydroxyphenethylamine) (DA) and vitamin $\mathrm{B}_{6}$ (pyridoxine). $\left(\mathrm{VB}_{6}\right)$ [11-16].

Ascorbic acid (AA) or vitamin $\mathrm{C}$ is a six carbon compound related to glucose, a potent reducing agent that readily and reversibly oxidizes to dehydroascorbic acid [17]. Ascorbic acid is present in all animal and plant cells, especially in free form and also bound to proteins. Vitamin $\mathrm{C}$ is involved in the formation of collagen and inhibits the action of tyrosinase, an enzyme that catalyzes the production of melanin, and plays a key role in the recycling of vitamin $\mathrm{E}$ [18]. Vitamin C also participates in the synthesis of carnitine (enzyme) and 
cholesterol and improves immune function. It maintains the integrity of blood vessels and the health of teeth. Important in the healing of wounds and burns, in the absorption of iron and in the fight against free radicals. Prevents infections and scurvy (spontaneous mucosal bleeding, reduction in ossification and deficiency in healing processes) [19].

\section{Experimental}

\subsection{Materials}

All chemicals used were of reagent grade and deionized

$$
\begin{array}{cc}
-\mathrm{Si}(\mathrm{OH})_{3} & +\left(\mathrm{CH}_{3} \mathrm{O}\right)_{3} \mathrm{Si}\left(\mathrm{CH}_{2}\right)_{3} \mathrm{NH}_{2} \\
\text { 3APTS } & \mathrm{SiO}_{3} \mathrm{Si}\left(\mathrm{CH}_{2}\right)_{3} \mathrm{NH}_{2}+3 \mathrm{CH}_{3} \mathrm{OH} \\
\text { SF }-3 \text { APTS }
\end{array}
$$

Silica gel was degassed at $423 \mathrm{~K}$ under vacuum $\left(10^{-3} \mathrm{~atm}\right)$ for $8 \mathrm{~h}$. About $50 \mathrm{~g}$ this material was mixed with $30.0 \mathrm{~cm}^{3}$ of 3-aminopropyltrimethoxysilane dissolved in $400 \mathrm{~cm}^{3}$ of dry toluene. The mixture was stirred for $12 \mathrm{~h}$ under a dry nitrogen atmosphere at the temperature of the solvent reflux. The chemically modified silica was separated by filtration, washed with ethanol in a Soxhlet extractor for $24 \mathrm{~h}$ and finally dried at $353 \mathrm{~K}$ under vacuum $\left(10^{-3} \mathrm{~atm}\right)$. The solid was named SF-3APTS.

\subsection{Modification of the SF-3APTS Silica with EDTA}

In $10 \mathrm{~g}$ of SF-3APTS silica suspended in $50.0 \mathrm{~cm}^{3}$ of dry ethanol, EDTA reagent was added $\left(1.7 \times 10^{-3} \mathrm{~mol}\right)$. The mixture was refluxed under mechanical stirring for one hour, then filtered and washed with ethanol and anhydrous ethyl ether. Excess solvent was removed by placing the silica in oven at 323 $\mathrm{K}$ for $6 \mathrm{~h}$. The silica obtained was SF-3APTS/EDTA.

\subsection{Preparation of the $\mathrm{H}\left[\mathrm{Ru}(\mathrm{III}) \mathrm{Cl}_{2}\left(\mathrm{H}_{2} \mathrm{EDTA}\right)\right]$ Complex [10]}

It had been dissolved $10.0 \mathrm{~g}$ of ruthenium trichloride in 60.0 $\mathrm{cm}^{3}$ concentrate $\mathrm{HCl}$, in a porcelain capsule, water bath and under agitation with a glass baton. An orange solution was formed that was taken almost to the dryness. This process of evaporation was repeated many times, after $20.0 \mathrm{~cm}^{3}$ addition of doubly-distilled water. It was added, then, $12.0 \mathrm{~g}$ of $\mathrm{H}_{4}$ EDTA, suspended in $10.0 \mathrm{~cm}^{3}$ of water. It formed a viscose mass that was dissolved slowly by the addition of $60.0 \mathrm{~cm}^{3}$ of concentrated $\mathrm{HCl}$, under constant agitation. A precipitate was formed, dissolved, forming a dark oil that became an adherent mass. With the $20.0 \mathrm{~cm}^{3}$ addition of water, it had redissolution, and the solution again was evaporated. This procedure was carried out many times. It was added then, $50.0 \mathrm{~cm}^{3}$ of solution $6.0 \mathrm{~mol} \mathrm{dm}^{-3}$ of $\mathrm{HCl}$. The solution was kept in freezer for three hours, having had the formation of a yellow solid. This solid, of composition $\mathrm{H}\left[\mathrm{Ru}(\mathrm{III}) \mathrm{Cl}_{2}\left(\mathrm{H}_{2} \mathrm{EDTA}\right)\right]$, was separated for filtration, washed with ether/ethanol mixture.

\subsection{Adsorption of RuCl3 $x \mathrm{H}_{2} \mathrm{O}$ on SF-3APTS/EDTA Surface}

In $1.0 \mathrm{~g}$ of SF-3APTS/EDTA silica suspended in $10.0 \mathrm{~cm}^{3}$ water was employed throughout the experiments. Silica Gel (Merck), 3-aminopropyltrimethoxysilane (Synth), ethanol (Synth), ruthenium (III) chloride hydrated (Synth) and ethylenediaminetetraacetic acid (Synth) were used for all preparations. Graphite (Fluka), the pyridoxine (Merck), ascorbic acid (Merck) and dopamine (Sigma) were used.

\subsection{APTS Modified Agent Coated on the Silica Gel Surface}

Silica gel functionalized with 3-aminopr opyltrimethoxysilane group was obtained according to the reaction: of dry ethanol, $\mathrm{RuCl}_{3}$. $\mathrm{H}_{2} \mathrm{O}$ reagent was added $(0.10 \mathrm{~g})$. The mixture was mechanical stirring for one hour, then filtered and washed with ethanol and anhydrous ethyl ether. Excess solvent was removed by placing the silica in oven at $333 \mathrm{~K}$ for $2 \mathrm{~h}$. The silica obtained was SF-3APTS/EDTA/Ru (beige greenish coloration).

\subsection{Adsorption of $\left.\mathrm{H}_{[\mathrm{RuCl}}\left(\mathrm{H}_{2} \mathrm{EDTA}\right)\right]$ on SF-3APTS/EDTA Surface}

In $1.0 \mathrm{~g}$ of SF-3APTS/EDTA silica suspended in $10.0 \mathrm{~cm}^{3}$ of dry ethanol, $\mathrm{H}[\mathrm{RuCl} 2(\mathrm{H} 2 \mathrm{EDTA})]$ complex was added $(0.10 \mathrm{~g})$. The mixture was mechanical stirring for one hour, then filtered and washed with ethanol. Excess solvent was removed by placing the silica in oven at $333 \mathrm{~K}$ for $1 \mathrm{~h}$. The silica obtained was SF-3APTS/EDTA/Ru(EDTA).

\subsection{Characterization}

The amount of nitrogen in the sample of SF-3APTS and SF-3APTS/EDTA were quantified taking advantage of its basic character [20]. In a typical example, $0.200 \mathrm{mg}$ of the SF-AETS silica were added to $25.0 \mathrm{~cm}^{3}$ of standard $\mathrm{HCl}$ $\left(0.104 \mathrm{~mol} \mathrm{dm}^{-3}\right)$ solution in a thermostatized cell $(298 \mathrm{~K})$, reacting for one hour. The conductivity of the system was measured before and after the reaction. The excess of acid was determined by means of conductivity variation and used to calculate the amount of nitrogen sites.

The conductivity measurements were performed in a Conductivity CD-21 Digimed with immersion cell with platinized platinum electrode, using a magnetic shaker Tecnal TE 085 and bath thermostat Microquímica, MGBTZ 99-20 model with resolution \pm 0.1 .

\subsection{Electrochemical Measurements}

The modified carbon paste electrode was prepared by mixing $30 \mathrm{mg}$ of the silicas, $30 \mathrm{mg}$ of graphite and a drop of mineral oil $\left(2.0 \times 10^{-2} \mathrm{~cm}^{3}\right)$. The paste was deposited into a cavity on the surface of a platinum disk fused at the end of a glass tube with $1 \mathrm{~mm}$ inner diameter. This proportion was used due to a good response obtained with a preliminary test, after a detailed study of the paste composition.

The electrochemical measurements were made using this 
carbon paste electrode as the working electrode, $\mathrm{Ag} / \mathrm{AgCl}$ as reference electrode (satured $\mathrm{KCl}$ ) and a platinum wire as auxiliary electrode. The electrochemical properties were studied by means of cyclic voltammetry with a PAR 273A (EG\&G) potentiostat-galvanostat. All experiments were carried out in $0.10 \mathrm{~mol} . \mathrm{dm}^{-3}$ phosphate buffer supporting electrolyte solution under a pure argon atmosphere and the $\mathrm{pH}$ was adjusted by adding $\mathrm{HCl}$ or $\mathrm{NaOH}$ solutions. Different supporting electrolytes were also tested.

\subsection{Analytical Method of Successive Addition of Standard}

For the voltammetric determination of ascorbic acid in industrial fruit juice it was obtained the anodic peak current curve $(\mathrm{A})$ versus concentration of ascorbic acid added (([AA] $=1.73 \times 10^{-4}$ at $\left.5.06 \times 10^{-3} \mathrm{~mol} \mathrm{dm}^{-3}\right)$ or $\left([\mathrm{AA}]=3.98 \times 10^{-5}\right.$ at $\left.38.1 \times 10^{-5} \mathrm{~mol} \mathrm{dm}^{-3}\right)$ ).

These aliquots ranged from $0.100 \mathrm{~cm}^{3}$ to $0.500 \mathrm{~cm}^{3}$ of ascorbic acid solution $\left(1.40 \times 10^{-2} \mathrm{~mol} \mathrm{dm}^{-3}\right.$ or $8.00 \times 10^{-3} \mathrm{~mol}$ $\mathrm{dm}^{-3}$ ) were added in $20.0 \mathrm{~cm}$ of phosphate buffer $(\mathrm{pH} 6.86$ and $\mu=0.10 \mathrm{~mol} \mathrm{dm}^{-3}$ ), deaerated, which contained a certain volume of fruit juice (first experiment $3.00 \mathrm{~cm}^{3}$ and second $2,00 \mathrm{~cm}^{3}$ ) and the differential pulse voltamograms between 0.9 and $0.7 \mathrm{~V}$, after each addition.

The values of the quotient (linear coefficient / angular coefficient) obtained provided the concentration of ascorbic acid in the aliquot of juice in the total volume.

\section{Results and Discussion}

\subsection{Characterization}

For the SF-3APTS silica the amount of supported groups was determined by nitrogen analysis using the conductometric method described in the experimental part. The functionalization efficiency was determined for (silane) groups as being equal to $1.20 \pm 0.01 \mathrm{mmol} \mathrm{g}^{-1}$ in the SF3APTS based on the nitrogen content.

The number of groups supported on the SF-3APTS/EDTA, determined chronometrically, through the nitrogen (amides) analysis was $\left(1.00 \pm 0.01 \mathrm{mmol} \mathrm{g}^{-1}\right)$ corresponding to $0.50 \pm$ $0.01 \mathrm{mmol} \mathrm{g}^{-1}$ groups (EDTA supported).

\subsection{Electrochemical Behavior of the Modified Electrode}

\subsubsection{SF-3APTS/EDTA/Ru(EDTA) Sílica}

Cyclic voltammetric experiments using a carbon paste electrode modified with the material were carried out. For an electrode modified with only SF-3APTS/EDTA no current peaks are observed. However, a cyclic voltammetric curve for a carbon paste electrode prepared with SF-3APTS/EDTA having complexed $\mathrm{H}\left[\mathrm{Ru}(\mathrm{III}) \mathrm{Cl}_{2}\left(\mathrm{H}_{2}\right.\right.$ EDTA)] was obtained. In this case, a current peak is seen with a midpoint potential at $\mathrm{E}_{1 / 2}=-0.11 \mathrm{~V}($ vs $\mathrm{Ag} / \mathrm{AgCl})$, where $\mathrm{E}_{1 / 2}=\left(\mathrm{E}_{\mathrm{pa}}+\mathrm{E}_{\mathrm{pc}}\right) / 2$ and $E_{p a}$ and $E_{p c}$ are the observed anodic and cathodic peak potentials, respectively. This value was assigned to the pair $\mathrm{Ru}(\mathrm{III}) / \mathrm{EDTA} / \mathrm{Ru}(\mathrm{II}) / \mathrm{EDTA}$.

The stability of the electrode was evaluated cycling the potential several times. The peak current intensities do not demonstrate any decrease, indicating that the complexed $\mathrm{H}\left[\mathrm{Ru}(\mathrm{III}) \mathrm{Cl}_{2}\left(\mathrm{H}_{2}\right.\right.$ EDTA $\left.)\right]$ strongly adheres to the SF$3 \mathrm{APTS} / \mathrm{EDTA}$ and is not released to the solution phase under the operating conditions.

Cyclic voltammograms obtained at different scan rates indicate that the value of $\Delta \mathrm{E}_{\mathrm{p}}\left(\Delta \mathrm{E}_{\mathrm{p}}=\mathrm{E}_{\mathrm{pa}}-\mathrm{E}_{\mathrm{pc}}\right)$ increases at higher ratios (Figure 1). This result reflects that the kinetics of electron transfer on the electrode surface is not sufficiently fast, as a consequence of having a matrix with considerable resistance. The correlation of the peak current, $I_{p a}$ and $I_{p c}$, against $v^{1 / 2}$ ( $v$ is the scan rate) is linear, which is very similar to a diffusion controlled process $[21,22]$. Since the electroactive species strongly adheres to the matrix, as it was shown earlier, the mechanism may be explained by the transport of the ion of the supporting electrolyte from the electrode surface for charge compensation [23, 24]. The nature of the supporting electrolyte varying the cation and anion (phosphate buffer, $\mathrm{KCl}, \mathrm{NH}_{4} \mathrm{Cl}, \mathrm{NaNO}_{3}$ and $\mathrm{NH}_{4} \mathrm{NO}_{3}$ ) did not produce any significant influence on $\mathrm{E}_{1 / 2}$. These results indicate that the supporting electrolytes are not interacting with the matrix surface and produce no significant change in the midpoint potential. It was also observed that the ion, independent of the hydrated radius, could compensate the charge. A similar behavior was also observed in hexacyanoferrate (II)-ruthenium (III) complex immobilized on silica gel surface chemically modified with zirconium (IV) oxide [25].

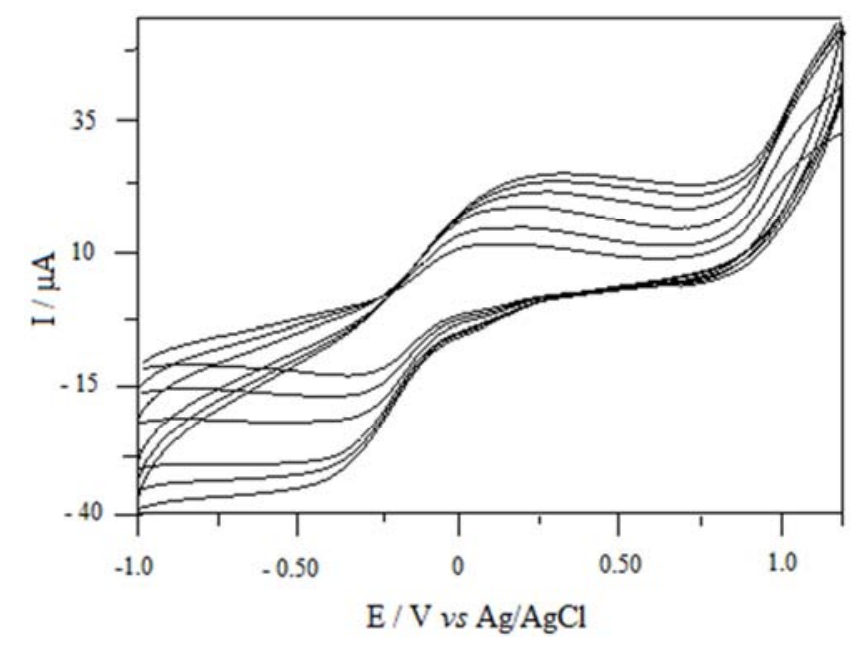

Figure 1. Cyclic voltammograms curves for the SF-3APTS/EDTA/Ru(EDTA) electrode in phosphate buffer, $\mathrm{pH}=6.86, \mu=0.10 \mathrm{~mol} \mathrm{dm^{-3 }}, 298 \mathrm{~K}$, in function of the scan rate: $\left(5,10,20,30,40\right.$ and $\left.50 \mathrm{mVs}^{-1}\right)$.

With this electrode, it was made a study about the oxidation of ascorbic acid, using differential pulse voltammetry, in conditions of $25 \mathrm{mV}$ amplitude and $7.8 \mathrm{mV}$ $\left.\mathrm{s}^{-1}\right)(-0.8$ to $1.2 \mathrm{~V})$ vs $\left.\mathrm{Ag} / \mathrm{AgCl}\right)$, phosphate buffer, $\mathrm{pH}=6.86$, $\mu=0.10 \mathrm{~mol} \mathrm{dm}^{-3}, 298 \mathrm{~K}$. The Figure 2 shows the differential pulse voltammograms of the carbon paste electrode modified with SF-3APTS/EDTA/Ru(EDTA) with the addition of ascorbic acid, the anodic peak current increased significantly, when compared with that obtained at the modified carbon paste electrode. 


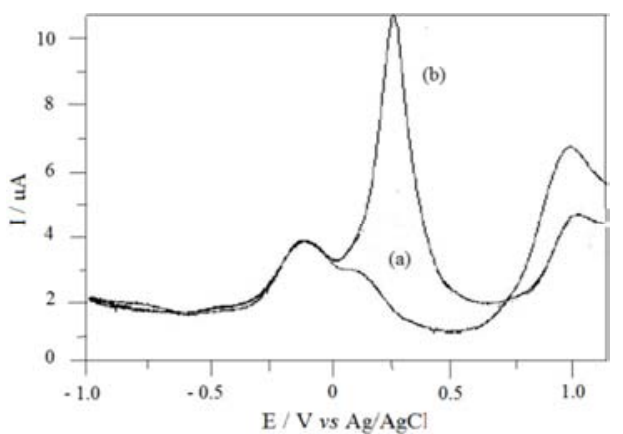

Figure 2. Differential pulse voltammogram curves for the $S F$ $3 A P T S / E D T A / R u(E D T A)$ electrode in the (a) absence and (b) presence of ascorbic acid in phosphate buffer, $\mathrm{pH}=6.86, \mu=0.10 \mathrm{~mol} \mathrm{dm}^{-3}, 298 \mathrm{~K}$.

The effect of several species (citric acid, tartaric acid, glucose, uric acid) on the anodic peak current at the modified electrode was evaluated and tested substances there was not interference on the electrode response. The reproducibility of the electrodes was investigated. Repetitive measurements were performed in ascorbic acid. The results of 100 successive measurements show a relative standard deviation of $1.0 \%$. Thus, the modified electrodes are very stable and good reproducibility is observed.

The performance of electrodes over a period of four months with measurements of the oxidation peak currents for ascorbic acid in phosphate buffer solution was observed on each consecutive day. This serves as an indicator of the stability of the modified electrodes toward ascorbic acid. The electrodes were used daily. The experimental results indicated that the current responses showed a relative standard deviation of $2.5 \%$, suggesting that the modified electrodes possess good stability.

\subsubsection{SF-3APTS/EDTA/Ru Sílica}

Figure 3 shows the electrochemical behavior at $20 \mathrm{mVs}^{-1}$, from -0.80 to $0.60 \mathrm{~V}(v \mathrm{sg} / \mathrm{gCl})$, by cyclic voltammetry of SF-3APTS/EDTA/Ru electrode, at $\mu=0.10 \mathrm{~mol} \mathrm{dm}^{-3}$, phosphate buffer, $\mathrm{pH}=6.86$ and at $298 \mathrm{~K}$, after electrode stability. However, a cyclic voltammetric curve for a carbon paste electrode prepared with SF-3APTS/EDTA having complexed $\mathrm{RuCl}_{3} \times \mathrm{H}_{2} \mathrm{O}$ was obtained. In this case, a current peak is seen with a midpoint potential at $\mathrm{E}_{1 / 2}=0.081 \mathrm{~V}(v s$ $\mathrm{Ag} / \mathrm{AgCl})$.

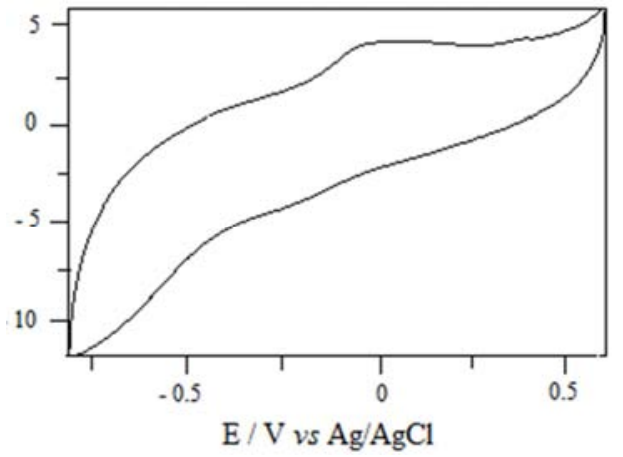

Figure 3. Cyclic voltammograms curve for the SF-3APTS/EDTA/Ru electrode in phosphate buffer, $\mathrm{pH}=6.86, \mu=0.10 \mathrm{~mol} \mathrm{dm}^{-3}, 298 \mathrm{~K}$. Scan rate $20 \mathrm{mVs}^{-1}$.
Figure 4 shows a comparison of electrochemical behavior by differential pulse voltammetry $(100 \mathrm{mV}$ of pulse amplitude and $\left.12 \mathrm{mVs}^{-1}\right)(-0.8$ a $1.2 \mathrm{~V}),\left(\mu=0.10 \mathrm{~mol} \mathrm{dm}^{-3}\right.$, phosphate buffer, $\mathrm{pH}=7.0 ; 298 \mathrm{~K}, v s \mathrm{Ag} / \mathrm{AgCl})$, of SF$3 \mathrm{APTS} / \mathrm{EDTA} / \mathrm{Ru}(\mathrm{EDTA})$ electrode, which showed the following peak values $\left(\mathrm{Ep}_{\mathrm{a} 1}=-0.110 \mathrm{~V} ; \mathrm{Ep}_{\mathrm{a} 2}=0.120 \mathrm{~V}\right.$ and $\mathrm{Ep}_{\mathrm{a} 3}=1.0 \mathrm{~V}$ ) (Figure 4a) with the SF-3APTS/EDTA)Ru electrode $\left(\mathrm{Ep}_{\mathrm{a} 1}=-0.099 \mathrm{~V}, \mathrm{Ep}_{\mathrm{a} 2}=0.023 \mathrm{~V}\right.$ and $\mathrm{Ep}_{\mathrm{a} 3}=0.977$ V) (Figure $4 \mathrm{~b}$ ), whose peak values are compatible with those of the $\mathrm{Ru}(\mathrm{II}) /(\mathrm{III})$ (EDTA.

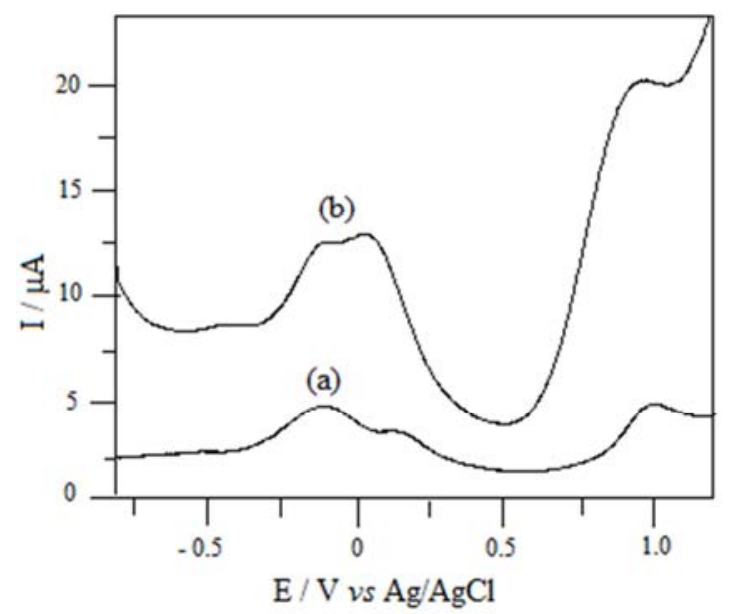

Figure 4. Differential pulse voltammogram curves for (a) SF3APTS/EDTA/Ru(EDTA) electrode and (b) SF-3APTS/EDTA/Ru electrode in phosphate buffer, $\mathrm{pH}=6.86, \mu=0.10 \mathrm{~mol} \mathrm{dm^{-3 }}, 298 \mathrm{~K}$.

The nature of the supporting electrolyte varying the cation and anion has also been studied and did not produce any significant influence on $\mathrm{E}_{1 / 2}$.

First it was done by differential pulse voltammetry with the SF-3APTS/EDTA/Ru electrode the study of the oxidation of ascorbic acid in the concentration range of $8.0 \times 10^{-5} \mathrm{~mol}$ $\mathrm{dm}^{-3}$ to $9.0 \times 10^{-4} \mathrm{~mol} \mathrm{dm}^{-3}\left(\mathrm{Ep}_{\mathrm{a}}=0.140\right.$ to $\left.0.223 \mathrm{~V}\right)$ as shown in the Figure 5. Figure 6a shows the electrochemical behavior of the ascorbic acid using SF-3APTS/EDTA/Ru electrode $\left(9.0 \times 10^{-4} \mathrm{~mol} \mathrm{dm}^{-3}\right)$ and glassy carbon $\left(\mathrm{Ep}_{\mathrm{a}}=0.260 \mathrm{~V}\right)$ (Figure 6b).

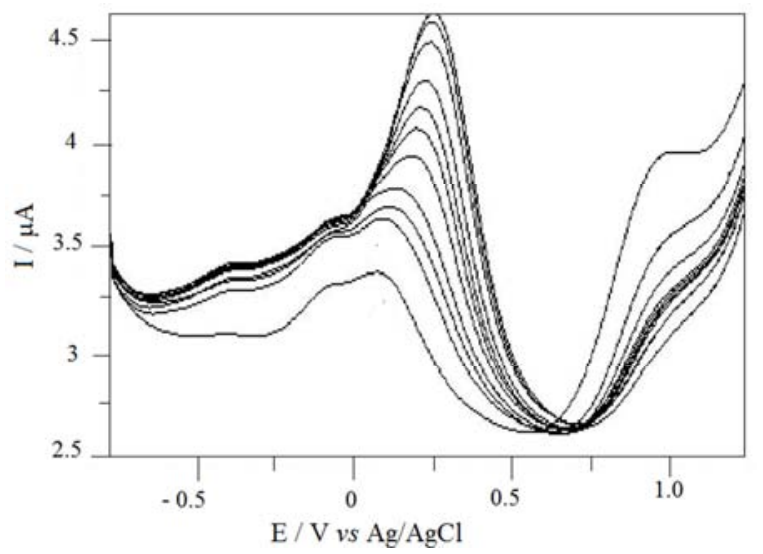

Figure 5. Electrochemical behavior of the SF-3APTS/EDTA/Ru electrode with added ascorbic acid concentration in the range $8.0 \times 10^{-5}$ to $9.0 \times 10^{-4}$ mol dm $\mathrm{m}^{-3}\left(20 \mathrm{mVs}^{-1}\right.$, phosphate buffer, $\left.\mathrm{pH}=7.0, \mu=0.10 \mathrm{~mol} \mathrm{dm}{ }^{-3}, 298 \mathrm{~K}\right)$. 


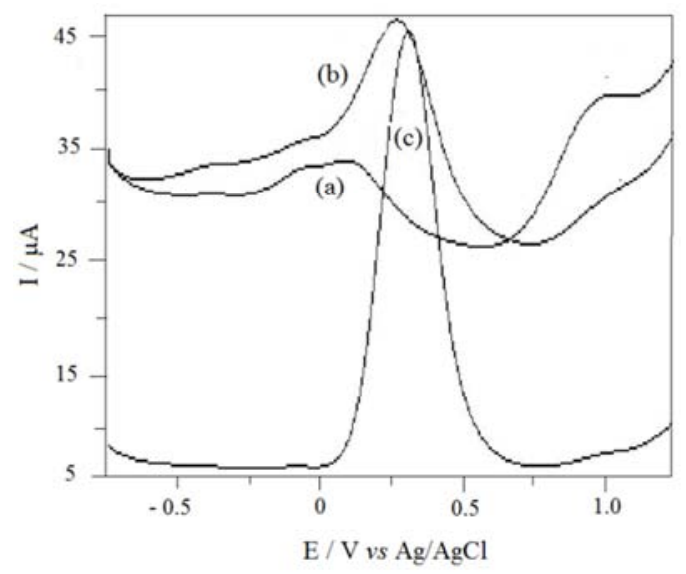

Figure 6. Differential pulse voltammogram in phosphate buffer, $p H 7.0$ and $\mu 0.10 \mathrm{~mol} \mathrm{dm} \mathrm{m}^{-3}, 298 \mathrm{~K}$. (a) and (b) SF-3APTS/EDTA/Ru electrode: (a) in the absence and (b) presence ascorbic acid $\left(9.0 \times 10^{-4} \mathrm{~mol} \mathrm{dm}^{-3}\right)$; (c) glassy carbon electrode: presence ascorbic acid $\left(9.0 \times 10^{-4} \mathrm{~mol} \mathrm{dm}^{-3}\right)$.

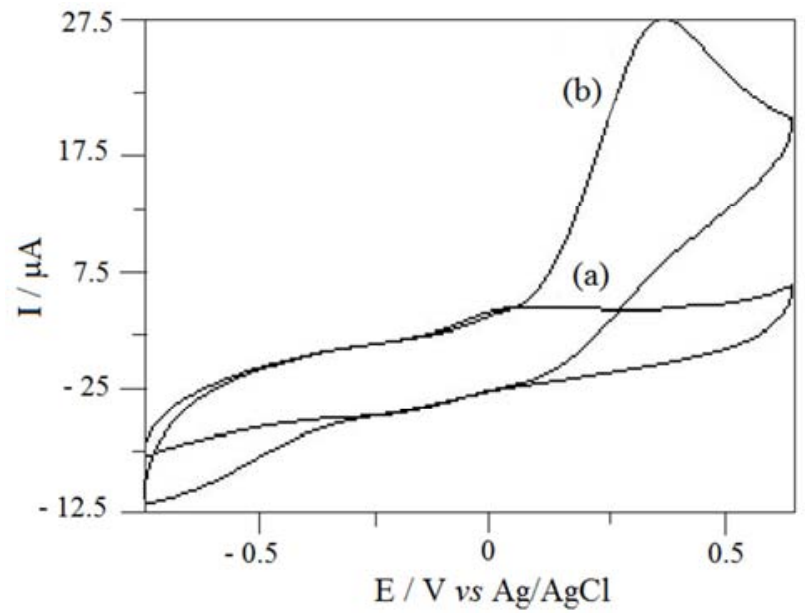

Figure 7. Ciclyc voltammogram curves for the SF-3APTS/EDTA/Ru electrode in the (a) absence and (b) presence of ascorbic acid $\left(9.0 \times 10^{-4} \mathrm{~mol}\right.$ $d^{-3}$ ) in phosphate buffer, $p H=6.86, \mu=0.10 \mathrm{~mol} \mathrm{dm}^{-3}, 298 \mathrm{~K}$. Scan rate 20 $m V s^{-1}$.

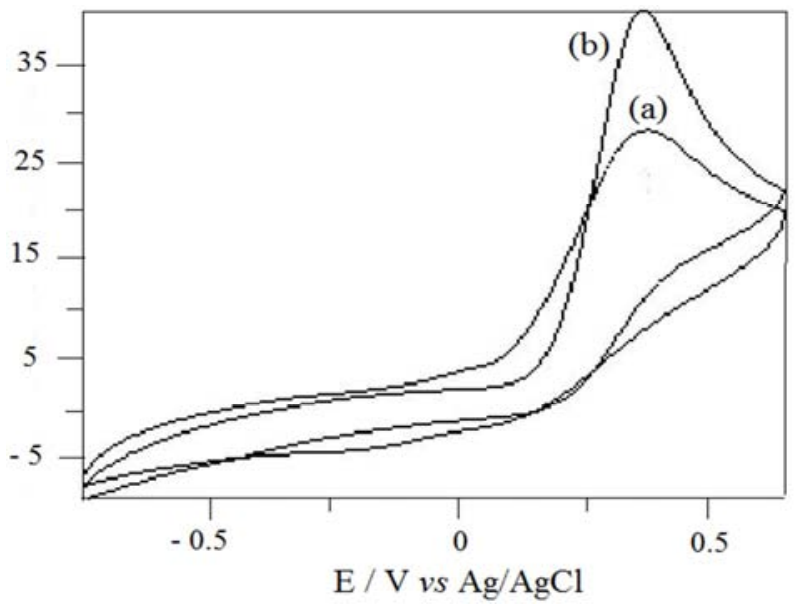

Figure 8. Ciclyc voltammogram curves for the SF-3APTS/EDTA/Ru electrode in the presence of ascorbic acid $\left(9.0 \times 10^{-4} \mathrm{~mol} \mathrm{dm}^{-3}\right)$ (a) and glassy carbon electrode in presence of ascorbic acid $\left(9.0 \times 10^{-4} \mathrm{~mol} \mathrm{dm}^{-3}\right)$ (b), in phosphate buffer, $p H=6.86, \mu=0.10 \mathrm{~mol} \mathrm{dm}^{-3}, 298 \mathrm{~K}$. Scan rate 20 $m V s^{-1}$.
Oxidation of ascorbic acid $\left(1.0 \times 10^{-4} \mathrm{~mol} \mathrm{dm}^{-3}\right)$ was also performed by cyclic voltammetry at $20 \mathrm{mVs}^{-1}$, from -0.80 to $0.60 \mathrm{~V}(v s \mathrm{Ag} / \mathrm{AgCl})$ with SF-3APTS/ EDTA/Ru, $(\mu=0.10$ mol dm${ }^{-3}$, phosphate buffer, $\mathrm{pH}=6.86$ and at $\left.298 \mathrm{~K}\right),\left(\mathrm{Ep}_{1}=\right.$ $0.301 \mathrm{~V})$ as shown in the Figures 7 and with glassy carbon $\left(E \mathrm{p}_{1}=0.311 \mathrm{~V}\right)$, Figure 8 .

The effect of several species on the anodic peak current at the modified electrode was also evaluated. Neither of those substances causes interference in the electrode response. The performance of electrodes over a period of six months with measurements of the oxidation peak currents for an ascorbic acid in phosphate buffer solution was observed on each consecutive day. This serves as an indicator of the stability of the modified electrodes toward ascorbic acid. The electrodes were used daily. The experimental results indicated that the current responses showed a relative standard deviation of $3.0 \%$, suggesting that the modified electrodes possess good stability.

The reproducibility of the electrodes was also investigated. Repetitive measurements were performed in ascorbic acid. The results of 200 successive measurements show a relative standard deviation of $1.1 \%$. Thus, the modified electrodes are very stable and good reproducibility is observed.

\subsubsection{Electroanalytical Determination of Ascorbic Acid in Guava Juice}

For the determination of ascorbic acid in guava juice, by pulse differential voltammetry $(50 \mathrm{mV}$ of pulse amplitude and $20 \mathrm{mVs}^{-1}$ in the range of -0.9 to $0.7 \mathrm{~V} v s . \mathrm{Ag} / \mathrm{AgCl}, \mu=$ $0.10 \mathrm{~mol} \mathrm{dm}^{-3}$, phosphate buffer, $\mathrm{pH}=6.86 ; 298 \mathrm{~K}$ ) was used successive pattern addition method, which was done in duplicate. The figures $9,10,11$ and 12 summarize the electrochemical behavior of ascorbic acid oxidation in guava juice SuFresh, using as working electrode the SF3APTS/EDTA/Ru electrode, what presented, after addition of $3.00 \mathrm{~cm}^{3}$ (or $2.00 \mathrm{~cm}^{3}$ ) guava juice, a double peak in the region of ascorbic acid oxidation $\left(\mathrm{Ep}_{\mathrm{a} 1}=0.230 \mathrm{~V}\right.$ and $\mathrm{Ep}_{\mathrm{a} 2}=$ $0.330 \mathrm{~V}$, vs. $\mathrm{Ag} / \mathrm{AgCl}$ ). Figures 9 and 10 show the differential pulse voltammograms of two samples of guava juice and Figures 11 and 12 their respective curves, obtained by standard addition method.

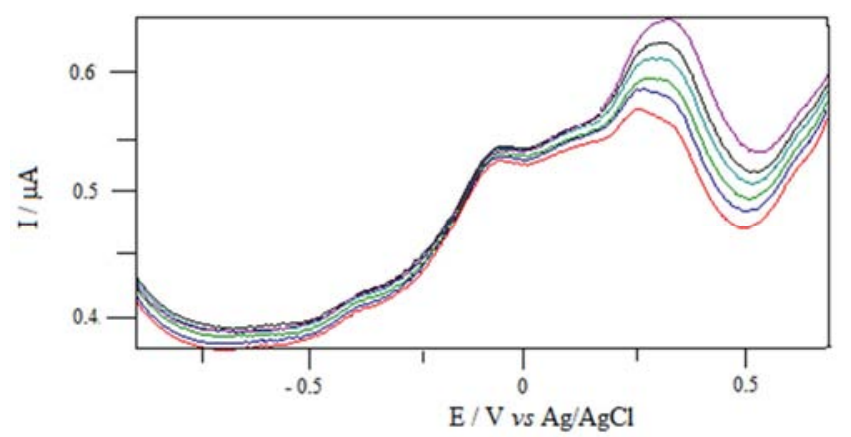

Figure 9. Differential pulse voltammograms obtained in the first juice sample guava $\left(3.00 \mathrm{~cm}^{3}\right)$, with SF-3APTS/EDTA/Ru electrode for different concentrations of ascorbic acid $\left(1.73 \times 10^{-4}\right.$ to $\left.5.06 \times 10^{-3} \mathrm{~mol} \mathrm{dm}^{-3}\right)$ in phosphate buffer, $p H=6.86, \mu=0.10 \mathrm{~mol} \mathrm{dm} \mathrm{m}^{-3}, 298 \mathrm{~K}(50 \mathrm{mV}$ pulse amplitude and $\left.20 \mathrm{mVs}^{-1}\right)$. 


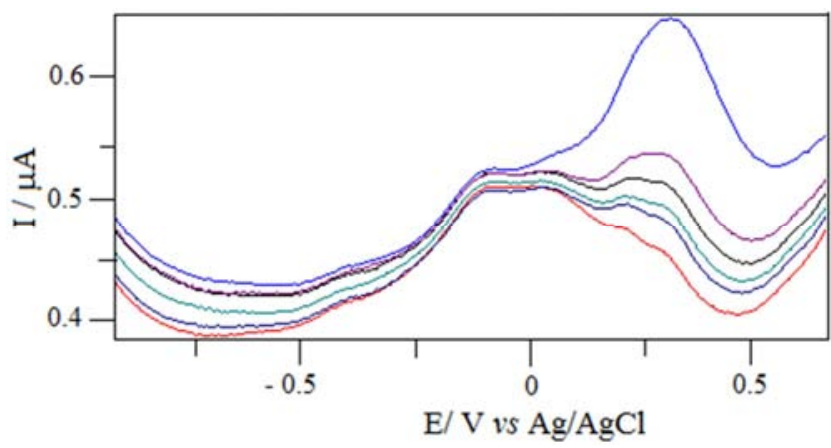

Figure 10. Differential pulse voltammograms obtained in the second juice sample guava $\left(2.00 \mathrm{~cm}^{3}\right)$, with $S F-3 A P T S / E D T A / R u$ electrode for different concentrations of ascorbic acid $\left(3.98 \times 10^{-5}\right.$ to $\left.38.1 \times 10^{-5} \mathrm{~mol} \mathrm{dm}^{-3}\right)$ in phosphate buffer, $\mathrm{pH}=6.86, \mu=0.10 \mathrm{~mol} \mathrm{dm^{-3 }}, 298 \mathrm{~K}(50 \mathrm{mV}$ pulse amplitude and $\left.20 \mathrm{mVs}^{-1}\right)$.

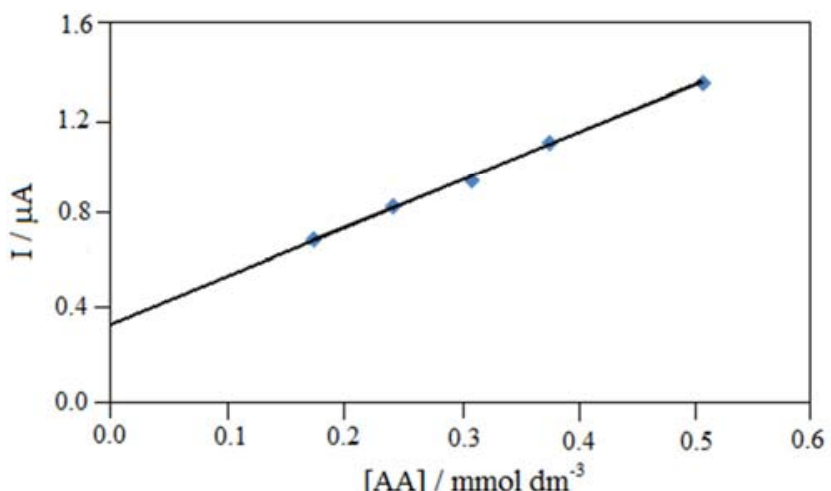

Figure 11. Graph of $I_{p a}$ versus concentration of the ascorbic acid $(1.73 \times 10$ ${ }^{4}$ to $5.06 \times 10^{-3} \mathrm{~mol} \mathrm{dm}^{-3}$ ) for the determination of ascorbic acid in the first guava juice sample.

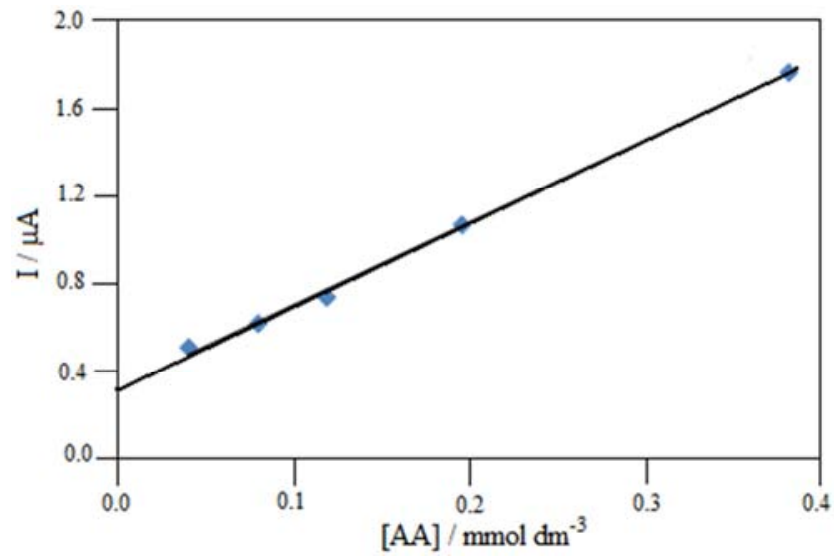

Figure 12. Graph of $I_{p a}$ versus concentration of the ascorbic acid $(3.98 \times 10$ ${ }^{5}$ to $38.1 \times 10^{-5} \mathrm{~mol} \mathrm{dm^{-3 }}$ ) for the determination of ascorbic acid in the second guava juice sample.

Table 1 shows the ascorbic acid contents found in two industrialized guava, using the method of successive addition of standard and the mean value found was $40.3 \pm 1.5 \mathrm{mg}$ ascorbic acid in $200 \mathrm{~cm}^{3}$ of fruit juice, which is in accordance with the value provided by the manufacturer $40 \mathrm{mg}$ ascorbic acid in $200 \mathrm{~cm}^{3}$ of the juice $\left(200 \mathrm{mg} \mathrm{dm}^{-3}\right)$.
Table 1. Determination of ascorbic acid (AA) in guava juice using differential pulse voltammetry, standard addition method.

\begin{tabular}{llll}
\hline $\begin{array}{l}\text { Samples of guava } \\
\text { juice }\end{array}$ & $\begin{array}{l}{[\mathbf{A A}] \mathbf{~ m o l}} \\
\mathbf{d m}^{-3}\end{array}$ & $\begin{array}{l}{[\mathbf{A A}] \mathbf{~ m g} /} \\
\mathbf{2 0 0 \mathbf { c m } ^ { 3 }}\end{array}$ & $\begin{array}{l}{[\mathbf{A A}] \mathbf{~ m g}} \\
\mathbf{d m}^{-3}\end{array}$ \\
\hline First & $11.8 \times 10^{-4}$ & 41.8 & 209 \\
Second & $11.0 \times 10^{-4}$ & 38.7 & 93 \\
Average & $11.4 \times 10^{-4}$ & $40.3 \pm 1.5$ & $201 \pm 8$ \\
\hline
\end{tabular}

\section{Conclusion}

The EDTA immobilized on 3-aminopropyltrimethoxysilane on silica gel surface was synthesized. The results obtained from the electrode containing $\mathrm{RuCl}_{3} \quad \mathrm{x} \quad \mathrm{H}_{2} \mathrm{O}$ and $\mathrm{H}\left[\mathrm{Ru}(\mathrm{III}) \mathrm{Cl}_{2}\left(\mathrm{H}_{2}\right.\right.$ EDTA $\left.)\right]$ were very promising. The advantages of using the proposed electrodes have been established by analytical procedures simple. The electrode did not show significant changes in response after four and six months of use for SF-3APTS/EDTA/Ru(EDTA) and SF-3APTS/EDTA/Ru, respectively, thus showing good chemical stability.

The SF-3APTS/EDTA/Ru electrode was used in electroanthic determinationoff ascorbic acid in industrial guava juice, because with SF-3APTS/EDTA/Ru(EDTA) no advantage was found. The use of this electrode showed to be efficient for the determination of ascorbic acid in industrialized fruit juices as an electroanalytical method.

\section{References}

[1] Sotomayor M D P T, Kubota L T (2002) Enzymeless biosensors: A novel area for the development of amperometric sensors. Quim Nova 25: 123-128.

[2] Iler R K (1979) The Chemistry of Silica, John Wiley \& Sons, New York.

[3] Gil E S, Melo G R (2010) Electrochemical biosensors in pharmaceutical analysis. Bras J Pharm Sci 46: 375-391.

[4] Ping J, Wu J, Ying Y, Wang M, Liu G, Zhang M (2011) Evaluation of Trace Heavy Metal Levels in Soil Samples Using an Ionic Liquid Modified Carbon Paste Electrode. J Agric Food Chem 59: 4418-4423.

[5] Ping J, Ru S, Fan K, Wu J, Ying Y (2010) Copper oxide nanoparticles and ionic liquid modified carbon electrode for the non-enzymatic electrochemical sensing of hydrogen peroxide. Microchim Acta 171:117-123.

[6] Vancara I, Vytřas K, Barek J, Zima J (2001) Carbon paste electrodes in modern electroanalysis. Crit Rev Anal Chem 31: 311-345.

[7] Raj C. R, Ohsaka T (2001) Electroanalysis of ascorbate and dopamine at a gold electrode modified with a positively charged self-assembled monolayer. J Electroanal Chem 496: 44-49.

[8] Carmo D R, Paim L L (2013) Investigation about the copper adsorption on the chloropropylsilica gel surface modified with a nanostructured dendrimer DAB-Am-16: an analytical application for determination of copper in different samples. Mater Res 16: 164-172. 
[9] Alothmanand A Z, Apblett W A (2010) Metal ion adsorption using polyamine-functionalized mesoporous materials prepared from bromopropyl-functionalized mesoporous silica. J Hazard Mater 182: 581-590.

[10] Lazarin A M, Sernaglia R L (2014) Spectrophotometric Characterization of the Complex Generated in Solution for the Reaction of $\mathrm{H}\left[\mathrm{Ru}(I I I) \mathrm{Cl}_{2}\left(\mathrm{H}_{2}\right.\right.$ EDTA $\left.)\right]$ Complex with AETS Modifier Agent. Open J. Synthesis Theory and Applications 3: 37-43.

[11] Molaakbar E, Mostafavi A, Beitollani H, Alizadeh R (014) Synthesis of $\mathrm{ZnO}$ nanorods and their application in the construction of a nanostructure-based electrochemical sensor for determination of levodopa in the presence of carbidopa. Analyst 139: 4356-4364.

[12] Beitollahi H, Tajik S, Jahani S (2016) Electrocatalytic Determination of Hydrazine and Phenol Using a Carbon Paste Electrode Modified with Ionic Liquids and Magnetic Coreshell $\mathrm{Fe}_{3} \mathrm{O}_{4} @ \mathrm{SiO}_{2} / \mathrm{MWCNT}$ Nanocomposite. Electroanalysis 28: 1093-1099.

[13] Beitollahi H, Gholami A, Ganjali M R (2015) Preparation, characterization and electrochemical application of $\mathrm{Ag}-\mathrm{ZnO}$ nanoplates for voltammetric determination of glutathione and tryptophan using modified carbon paste electrode. Mater Sci Eng C 57: 107-112.

[14] Beitollahi H, Kekooei S (2016) Application of a Modified $\mathrm{CuO}$ Nanoparticles Carbon Paste Electrode for Simultaneous Determination of Isoperenaline, Acetaminophen and N-acetylL-cysteine. Electroanalysis 28: 645-653.

[15] Beitollahi H, Ivari S G, Torkzadeh-Mahani M (2016) Voltammetric determination of 6-thioguanine and folic acid using a carbon paste electrode modified with $\mathrm{ZnO}-\mathrm{CuO}$ nanoplates and modifier. Mater Sci Eng C Mater Biol Appl 69: 128-133.

[16] Beitollahi H, Ebadinejad F, Shojaie F, Torkzadeh-Mahani M (2016) A magnetic core-shell $\mathrm{Fe}_{3} \mathrm{O}_{4} @ \mathrm{SiO}_{2} / \mathrm{MWCNT}$ nanocomposite modified carbon paste electrode for amplified electrochemical sensing of amlodipine and hydrochlorothiazide. Anal Methods 8: 6185-6193.

[17] Hacisevki A (2009) An overview of ascorbic acid biochemistry. J Fac Pharm 38: 233-255.

[18] Du J, Cullen $J J$, Buettner $G R$ (2012) Ascorbic acid: Chemistry, biology and the treatment of cancer. Biochim Biophys Acta 1826: 443-457.

[19] Chambial S, Dwivedi S, Shukla K K, Jhon P J, Sharma P (2013) Vitamin $\mathrm{C}$ in disease prevention and cure: An overview. Indian J Clin Biochem 28: 314-328.

[20] Filippov A P (19984) Model of reactions of complex formation by metal salts with electrically neutral ligands grafted to a surface. Theor Exp Chem 19: 427-433.

[21] Bard A J, Faulkner L R (1980) "in Electrochemical Methods, Fundamentals and Applications" Wiley \& Sons, New York, pp. 218.

[22] Cazula B B, Lazarin A M (2017) Development of chemically modified carbon paste electrodes with transition metal complexes anchored on silica gel. Mater Chem Phys 186: 470477.

[23] Kubota L T, Gushikem Y, Perez J, Tanaka A A (1995) Electrochemical properties of iron phthalocyanine immobilized on titanium (IV) oxide coated on silica gel surface. Langmuir 11: 1009-1013.

[24] Zaldivar G A P, Gushikem Y (1992) Thin (IV) oxide grafied on a sílica gel surface as a conducting substrate base for nickel hexacyanoferrate. J Electroanal Chem 337: 165-174.

[25] Panice L B, Oliveira E A, Molin Filho R A D, Oliveira D P, Lazarin A M, Andreotti E I S, Sernaglia R L, Gushikem Y (2014) Electrochemical properties of the hexacyanoferrate (II)-ruthenium (III) complex immobilized on silica gel surface chemically modified with zirconium (IV) oxide. Mater Sci Eng B 188: 78-83. 